\title{
Impact of type of salt and ambient conditions on saline water evaporation from porous media
}

DOI:

10.1016/j.advwatres.2017.05.004

\section{Document Version}

Accepted author manuscript

Link to publication record in Manchester Research Explorer

\section{Citation for published version (APA):}

Shokri, S., Norouzi Rad, M., Webb, C., \& Shokri, N. (2017). Impact of type of salt and ambient conditions on saline water evaporation from porous media. Advances in Water Resources, 105, 154-161.

https://doi.org/10.1016/j.advwatres.2017.05.004

\section{Published in:}

Advances in Water Resources

\section{Citing this paper}

Please note that where the full-text provided on Manchester Research Explorer is the Author Accepted Manuscript or Proof version this may differ from the final Published version. If citing, it is advised that you check and use the publisher's definitive version.

\section{General rights}

Copyright and moral rights for the publications made accessible in the Research Explorer are retained by the authors and/or other copyright owners and it is a condition of accessing publications that users recognise and abide by the legal requirements associated with these rights.

\section{Takedown policy}

If you believe that this document breaches copyright please refer to the University of Manchester's Takedown Procedures [http://man.ac.uk/04Y6Bo] or contact uml.scholarlycommunications@manchester.ac.uk providing relevant details, so we can investigate your claim.

\section{OPEN ACCESS}




\section{Accepted Manuscript}

Impact of type of salt and ambient conditions on saline water evaporation from porous media

Salomé M.S. Shokri-Kuehni, Mansoureh Norouzirad, Colin Webb , Nima Shokri

PII: S0309-1708(17)30325-1

DOI: 10.1016/j.advwatres.2017.05.004

Reference: ADWR 2844

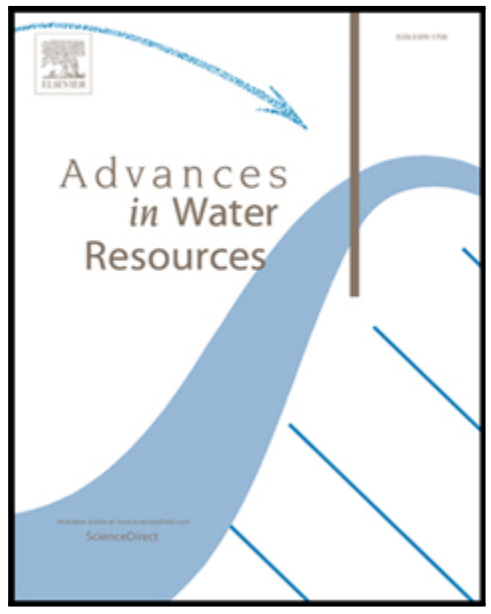

To appear in:

Advances in Water Resources

Received date:

2 April 2017

Revised date:

4 May 2017

Accepted date:

7 May 2017

Please cite this article as: Salomé M.S. Shokri-Kuehni, Mansoureh Norouzirad, Colin Webb, Nima Shokri , Impact of type of salt and ambient conditions on saline water evaporation from porous media, Advances in Water Resources (2017), doi: 10.1016/j.advwatres.2017.05.004

This is a PDF file of an unedited manuscript that has been accepted for publication. As a service to our customers we are providing this early version of the manuscript. The manuscript will undergo copyediting, typesetting, and review of the resulting proof before it is published in its final form. Please note that during the production process errors may be discovered which could affect the content, and all legal disclaimers that apply to the journal pertain. 


\section{HIghlights}

- Evaporation from porous media saturated with different salt solutions was investigated

- Effects of ambient temperature, relative humidity and type of salt were discussed

- Salt precipitation does not necessarily limit the evaporative flux

- Strong direct correlation between evaporation and surface salt precipitation was found

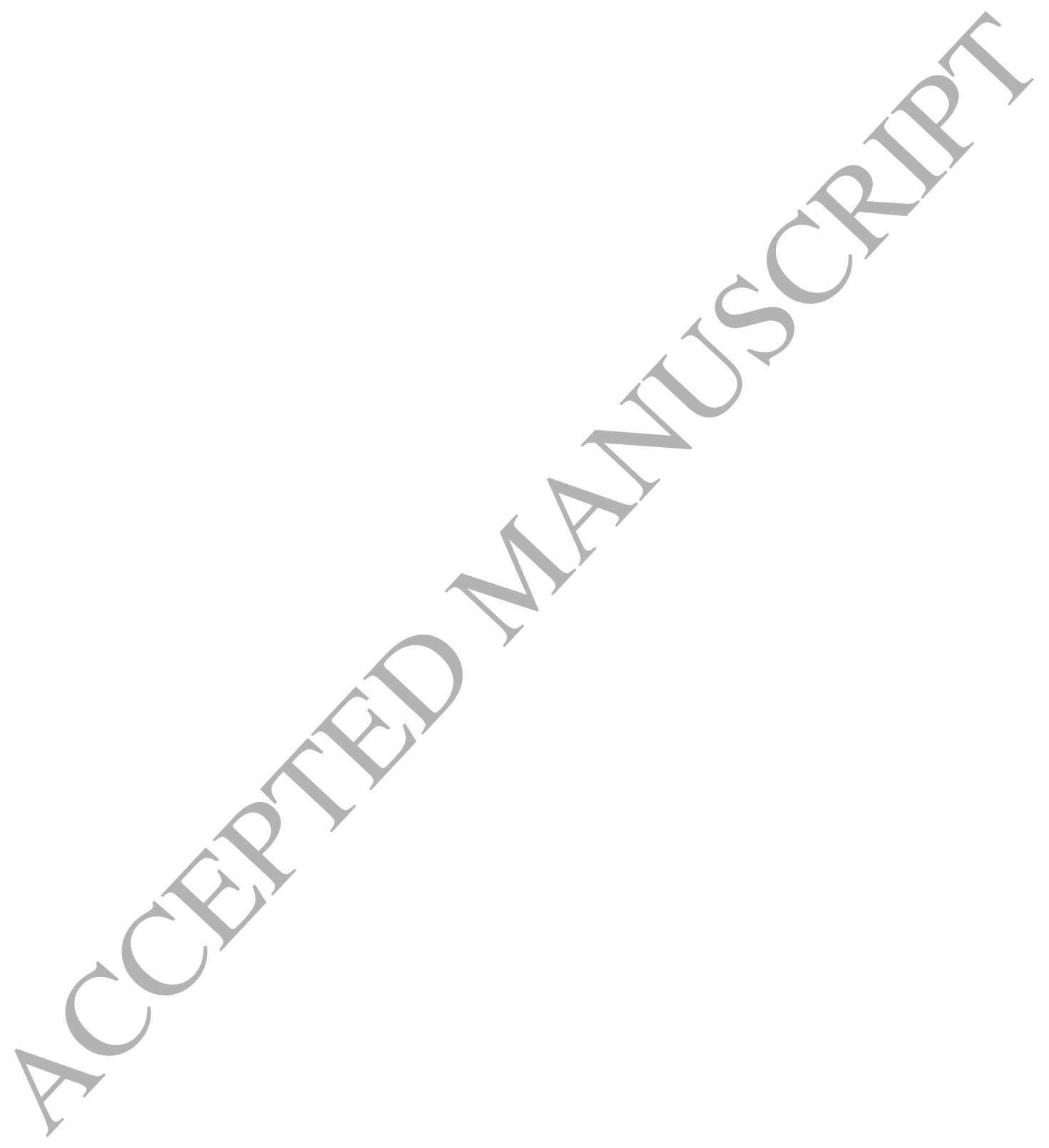


Impact of type of salt and ambient conditions on saline water evaporation from porous media

Salomé M.S. Shokri-Kuehni(1), Mansoureh Norouzirad(2), Colin Webb(1), Nima Shokri*(1)

(1) School of Chemical Engineering and Analytical Science, The University of Manchester, Manchester, UK

(2) Carl Zeiss Microscopy LLC, CA, The USA

*Corresponding author

Dr. Nima Shokri

School of Chemical Engineering and Analytical Science

Room C26, The Mill

The University of Manchester

Sackville Street, Manchester, M13 9PL, UK

Tel: 0441613063980

Email: nima.shokri@manchester.ac.uk 
Group website: http://personalpages.manchester.ac.uk/staff/nima.shokri/

\section{Abstract}

Saline water evaporation from porous media is important in many processes such as soil salinization, $\mathrm{CO}_{2}$ sequestration, crop production and water management. This process is influenced by the transport properties of porous media, properties of the evaporating solution and external conditions. In this work, we investigated the effects of external conditions and type of salt on the drying behaviour of sandy media and on the dynamics of surface salt precipitation. To do so, a comprehensive series of evaporation experiments were conducted using 33 columns packed with sand saturated with salt solutions. The evaporation experiments were conducted in an environmental chamber to investigate the effects of relative humidity, ambient temperature and type of salt on the evaporation process. Sodium Chloride, Calcium Chloride and Potassium Iodide with a wide range of concentration were used to saturate the sand columns mounted on digital balances. A digital camera was fixed at the surface of the sand packs to record the dynamics of salt precipitation at the surface. The results provide further confirmation that ambient conditions are the controlling factors during stage-1 evaporation of pure water. Additionally, the minor impact of the presence of precipitated salt at the surface on the saline water evaporation during the early stages of the process is discussed. Strong correlations between the cumulative water losses and the precipitation at the surface were found under different ambient conditions. The results obtained from different types of salt highlight the significant influence of the relationship between the saturated vapour pressure and salt concentration on the general dynamics of the process. 


\section{Introduction}

Saline water evaporation from porous media is an important topic in many hydrological processes which influence plant growth and vegetation, water balance, soil stability, beach intertidal zone processes and land-atmosphere interaction (Odeh and Onus, 2008; Deinlein et al., 2014; González-Alcaraz ET AL., 2014; Jambhekar et al., 2015; Geng et al., 2016). It is controlled by complex interactions between type of salt, transport properties of the porous media and external conditions (e.g. ambient temperature and relative humidity, wind, solar radiation). This has motivated many researchers to look into the effects of various parameters such as wettability [Sghaier and Prat, 2009; Bergstad and Shokri, 2016], particle size distribution [Eloukabi et al., 2013; Noruzirad et al., 2015], relative humidity [Gupta et al., 2014] and mixture of salt [Jambhekar et al.,2016] on the general dynamics of saline water evaporation from porous media.

An issue that has not received much attention in the literature is the effect of ambient conditions and the type of salt on the saline water evaporation from porous media. Sodium chloride $(\mathrm{NaCl})$ has been used as the model salt in the majority of previous papers to understand processes occurring during salty water evaporation from porous media. However, depending on the type of salt, the thermodynamics of the evaporating solution will be modified and this impacts the drying dynamics. Therefore, the findings regarding $\mathrm{NaCl}$ cannot necessarily be generalised for other types of salt in porous media. Considering the variety of salts available in the environment, it is essential to understand how water evaporation is modified when other salts are present in porous media.

Furthermore, compared to the effects of transport properties of porous media, far fewer studies have been performed to understand the effects of external conditions on saline water 
evaporation from porous media. A small increase in ambient temperature modifies soil water evaporation thus influencing salt transport and distribution in soil. Although the effects of atmospheric conditions on pure water evaporation from porous media are relatively wellunderstood [Smits et al., 2012; Haghighi et al., 2013; Aminzadeh and Or, 2013; Salvucci and Gentine, 2013; Ben Neriah et al., 2014; Vanderborght et al., 2017], their effects on saline water evaporation and the associated salt precipitation patterns are surprisingly not very advanced. Such knowledge will become even more important in the near future with the advent of climate change. Fluctuations in saline water evaporation and the potential change in salt balance in the environment caused by rising temperature (as a result of climate change) is complex and requires multidisciplinary research to understand the various aspects of this process [Austin et al., 2010].

Motivated by the importance of saline water evaporation from soil and its consequences on various hydrological processes, the specific objectives of the present study were to determine the effects of ambient temperature and relative humidity together with type of salt on water evaporation from porous media. Within this context, we have conducted several rounds of evaporation experiments using different types of salt in a climate chamber where we could control the ambient conditions accurately. These experiments have enabled us to understand how the relative humidity and ambient temperature, as well as the type of salt, influence the evaporation process from porous media.

\section{Theoretical considerations}

\subsection{Pure water evaporation from porous media}

As illustrated in other papers, for a given porous medium the rate of water evaporation is limited by the properties of the evaporating solution and the atmospheric conditions. As a first approximation, by neglecting the advective effects [Schlünder, 1988], the rate of volume 
change of the liquid $V\left(\mathrm{~m}^{3}\right)$ across the surface of porous media under isothermal conditions can be expressed using Fick's law [Gupta et al., 2014]:

$$
\frac{d V}{d t}=D \frac{A}{\rho} \frac{M}{R T} \frac{P_{s}-P_{\infty}}{\delta}
$$

where $D$ is the diffusion coefficient of the liquid in air $\left(\mathrm{m}^{2} \mathrm{~s}\right), A\left(\mathrm{~m}^{2}\right)$ is the surface area available for evaporation, $\rho$ is the density of the liquid $\left(\mathrm{kg} \mathrm{m}^{-3}\right), M$ is the molecular mass of water $\left(\mathrm{kg} \mathrm{mol}^{-1}\right), R$ is the gas constant $\left(\mathrm{kg} \mathrm{m}^{2} \mathrm{~s}^{-2} \mathrm{~K}^{-1} \mathrm{~mol}^{-1}\right), T$ is the temperature $(\mathrm{K}), P_{S}$ and $P_{\infty}$ correspond to the saturated vapour pressure above the evaporation surface and the vapour pressure in the surrounding environment respectively and $\delta$ is the thickness of the viscous boundary layer formed above the surface through which the diffusion of water vapour into ambient air takes places [Shokri et al., 2008]. Note that $P_{S}$ and $P_{\infty}$ are related via $P_{\infty}=R H \times$ $P_{S}$ where $R H$ corresponds to the relative humidity of the ambient air (\%).

According to Eq. (1), water evaporation depends on the vapour pressure gradient which is influenced by the temperature. The dependency of the saturated vapour pressure of water as a function of temperature $T$ can be expressed using the following empirical expression [Buck, 1981]:

$$
P_{S}(T)=0.61 \exp \left(\frac{17.27 T}{T+237.3}\right)
$$

In Eq. (2), the units of $T$ and $P_{S}$ are ${ }^{\circ} \mathrm{C}$ and $\mathrm{kPa}$, respectively. In addition to the saturated vapor pressure, the diffusion coefficient also depends on temperature, with the following equation describing this dependency [Ben Neriah et al., 2014]:

$$
D=2.23 \times 10^{-5}\left(\frac{T+273.15}{273.15}\right)
$$


In Eq. (3), the units of $T$ and $D$ are ${ }^{\circ} \mathrm{C}$ and $\mathrm{m}^{2} / \mathrm{s}$, respectively. Note that Eq. (1) can be used to estimate the evaporation rate in the early stages of the process, during so-called stage-1 evaporation [Shokri et al., 2009]. During this period, capillary induced liquid flow from large pores, at the receding interface between the saturated and unsatuarted zones to the $\mathrm{f}$ pores at the surface, keeps the surface wet and the evaporative demand is mainly supplied by liquid vaporization occurring at the surface of the porous media. However, when the liquid continuity with the surface is disconnected, the liquid vaporization occurs inside the medium and the drying process will be limited by vapour diffusion through the dry layer formed close to the surface of the porous media [Shokri et al., 2009].

Under a constant ambient temperature, $P_{S}$ remains constant. In such cases, the humidity will be the main factor determining the magnitude of the evaporation [Gupta et al., 2014]. Here we use $P_{s}, T$, and $D$ for water to scale time $\tilde{t}$ as:

$\tilde{t}=\frac{M D(1-R H) P_{s}}{\rho R T} t$

Using Eq. (4) and defining the constant $\beta$ as $A / \delta$, Eq. (1) becomes:

$\frac{d V}{d \tilde{t}}=\beta$

Since $\beta$ is not a function of temperature, Eq. (5) implies that all water evaporation data obtained at different humidities and temperatures should result in the single value $\beta$ (Soulié et al., 2015) if plotted versus the scaled $t$ introduced in Eq. (4). Note that this is valid only during stage -1 evaporation where the surface is wet and the bulk of the evaporative demand is supplied by the liquid vaporization at the interface between the air and the porous media surface. 


\subsection{Saline water evaporation from porous media}

The same approach explained in section 2.1 can be used to estimate saline water evaporation from porous media. However, there are some additional factors that must be taken into account as the properties of the saline solution (e.g. saturated vapour pressure, diffusion coefficient and density) change not only because of the variation of temperature but also because of changes in the concentration of solute.

In the present study, we have worked with three different salts namely $\mathrm{NaCl}, \mathrm{CaCl}_{2}$ and $\mathrm{KI}$. We obtained the following empirical equation to estimate saturated vapour pressure as a function of salt concentration using the values derived from Patil et al. (1991) and Clarke and Glew (1985):

$P_{S}=a_{0}+a_{1} C+a_{2} C^{2}+a_{3} C^{3}$

with $C$ indicating the salt concentration in molality and $P_{S}$ in $\mathrm{kPa}$. The fitting parameters $a_{1}, a_{2}$ and $a_{3}$ for $\mathrm{NaCl}, \mathrm{CaCl}_{2}$ and $\mathrm{KI}$ at $35^{\circ} \mathrm{C}$ are listed in Table 1 and are used later in our analysis. More details about how the fitting parameters in Table 1 were obtained using Eq. (6) are presented in the appendix.

Table 1. Parameters required to relate $P_{S}$ to salt concentration for the cases of $\mathrm{NaCl}, \mathrm{CaCl}_{2}$, and $\mathrm{KI}$ at $35^{\circ} \mathrm{C}$.

\begin{tabular}{|c|c|c|c|c|}
\hline Salt & $a_{0}$ & $a_{1}$ & $a_{2}$ & $a_{3}$ \\
\hline $\mathrm{NaCl}$ & 5.9762 & -0.3994 & 0.0086 & 0.0018 \\
& & & & \\
\hline $\mathrm{CaCl}_{2}$ & 5.16 & -0.1105 & -0.1348 & 0.0115 \\
& & & & \\
\hline
\end{tabular}




\begin{tabular}{|l|l|l|l|l|}
\hline KI & 5.5529 & -0.0673 & -0.0294 & 0.0016 \\
\hline
\end{tabular}

Additionally, the density and diffusion coefficient of salt are modified as the concentration of salt and ambient temperature changes. Published data on the dependency of diffusion coefficient of water molecules into air in the presence of ions in solution and its variation with respect to the type of salt and temperature are scarce, even for $\mathrm{NaCl}$ (note that here we are not referring to the self-diffusion coefficient of ions in liquid). Thus for salt solutions, the scaled time proposed in Eq. (4) will be useful only if the relationship between the salt concentration and the diffusion coefficient at a given temperature and solution density is known. If it is not, in the case of salt solution, one can scale time using Eq. (7) expressed as:

$\tilde{t}_{s}=\frac{M(1-R H) P_{s}}{\rho R T} t$

Substituting Eq. (7) into Eq. (8) leads to:

$\frac{d V}{d \tilde{t}_{s}}=\beta D$

Note that if the variation of diffusion coefficient with respect to salt concentration could be neglected, as is the case for pure water, cumulative mass loss curves measured at different temperature and relative humidity under different salt concentrations should be represented by a single curve (as long as the vaporization occurs at the surface of the porous media and the presence of a salt crust does not limit the process).

When salt is present in the evaporating liquid, its concentration increases over time as a result of evaporation. When the salt concentration substantially exceeds the solubility limit (i.e., supersaturation exceeds a critical value), crystals will precipitate by first nucleating and then growing. One of the key objectives of this paper was to investigate how the presence of 
precipitated salt influences the validity and applicability of the above analysis (Eqs. 5 and 8 ). The remainder of this paper evaluates the relative importance of ambient temperature and humidity on the evaporation from porous media in the absence and presence of three different salt.

\section{Experimental considerations}

Six sets of experiments were conducted in an environmental chamber in which the relative humidity and ambient temperature were controlled accurately and kept constant at the desired values in each set (Table 2). $\mathrm{NaCl}, \mathrm{CaCl}_{2}$ and $\mathrm{KI}$ with a wide range of concentration (Table 2) were used in our experiments to prepare salty solutions. Glass Hele-Shaw cells $(80 \mathrm{~mm}$ in width, $260 \mathrm{~mm}$ in height and $10 \mathrm{~mm}$ in thickness) and cylindrical glass columns (85 $\mathrm{mm}$ in diameter and $230 \mathrm{~mm}$ in height) were used in our experiments to pack sand particles saturated with either water or salty solutions. All boundaries of sand columns were closed except the top which was open to air for evaporation. The sand columns were mounted on digital balances (accuracy $0.01 \mathrm{~g}$ ) connected to a computer to record the mass of the evaporating sand packs every 5 minutes. A digital camera was fixed at the surface of the cylindrical column to record the dynamics of precipitation at the surface each hour. The camera was connected to a computer for automatic image acquisition. A total of 33 columns were packed with saturated sand packs to investigate the saline water evaporation under a variety of conditions in terms of relative humidity, ambient temperature and salt compound. More details about the boundary conditions in each experiment are presented in Table 2.

Table 2. Experimental conditions in each set of experiment. Note that in set \# 1, 2, and 3 the average sand particle size was $0.61 \mathrm{~mm}$ and in set \# 4, 5, and 6 it was $0.7 \mathrm{~mm}$.

\begin{tabular}{|l|l|l|l|l|}
\hline \# of & Evaporating & Salt & Ambient temperature & Dimension of the column \\
\hline
\end{tabular}




\begin{tabular}{|c|c|c|c|c|}
\hline set & liquid & $\begin{array}{l}\text { concentration } \\
\text { (M) }\end{array}$ & and relative humidity & \\
\hline 1 & Pure water & 0 & $\begin{array}{l}\text { Round 1: At } 25^{\circ} \mathrm{C} \\
\text { and } \mathrm{RH} \text { of } 30 \%, 50 \% \\
\text { and } 70 \% \\
\text { Round 2: At } 35^{\circ} \mathrm{C} \\
\text { and } \mathrm{RH} \text { of } 30 \%, 50 \% \\
\text { and } 70 \%\end{array}$ & $\begin{array}{l}\text { Hele-Shaw cell (80 } \mathrm{mm} \text { in } \\
\text { width, } 260 \mathrm{~mm} \text { in height } \\
\text { and } 10 \mathrm{~mm} \text { in thickness) }\end{array}$ \\
\hline 2 & $\begin{array}{c}\mathrm{NaCl} \\
\text { solution }\end{array}$ & 1 Molal & $\begin{array}{l}\text { Round } 1: \mathrm{At} 25^{\circ} \mathrm{C} \\
\text { and } \mathrm{RH} \text { of } 30 \%, 50 \% \\
\text { and } 70 \% \\
\text { Round } 2 \text { : At } 35^{\circ} \mathrm{C} \\
\text { and } \mathrm{RH} \text { of } 30 \%, 50 \% \\
\text { and } 70 \%\end{array}$ & $\begin{array}{l}\text { Hele-Shaw cell }(80 \mathrm{~mm} \text { in } \\
\text { width, } 260 \mathrm{~mm} \text { in height } \\
\text { and } 10 \mathrm{~mm} \text { in thickness) }\end{array}$ \\
\hline 3 & $\mathrm{NaCl}$ & 3 Molal & $\begin{array}{l}\text { Round } 1 \text { : At } 25^{\circ} \mathrm{C} \\
\text { and } \mathrm{RH} \text { of } 30 \% \text { and } \\
50 \% \\
\text { Round 2: At } 35^{\circ} \mathrm{C} \\
\text { and } \mathrm{RH} \text { of } 30 \% \text { and } \\
50 \%\end{array}$ & $\begin{array}{l}\text { Cylindrical column }(85 \mathrm{~mm} \\
\text { in diameter, } 230 \mathrm{~mm} \mathrm{in} \\
\text { height })\end{array}$ \\
\hline 4 & $\mathrm{NaCl}$ & $0.5,1,2,3,4,5$ & At $35^{\circ} \mathrm{C}$ and $\mathrm{RH}$ of & $\begin{array}{l}\text { Cylindrical column (83 mm } \\
\text { in diameter, } 153 \mathrm{~mm} \text { in }\end{array}$ \\
\hline
\end{tabular}




\begin{tabular}{|c|c|c|c|c|}
\hline & solution & Molal & $25 \%$ & height) \\
\hline 5 & KI solution & $\begin{array}{c}0.5,1,2,5,7 \\
\text { Molal }\end{array}$ & $\begin{array}{l}\text { At } 35^{\circ} \mathrm{C} \text { and } \mathrm{RH} \text { of } \\
25 \%\end{array}$ & $\begin{array}{l}\text { Cylindrical column }(83 \mathrm{~mm} \\
\text { in diameter, } 153 \mathrm{~mm} \text { in } \\
\text { height })\end{array}$ \\
\hline 6 & $\begin{array}{l}\mathrm{CaCl}_{2} \\
\text { solution }\end{array}$ & $\begin{array}{c}0.5,1,2,3.5,5, \\
6.5 \text { Molal }\end{array}$ & $\begin{array}{l}\text { At } 35^{\circ} \mathrm{C} \text { and } \mathrm{RH} \text { of } \\
25 \%\end{array}$ & $\begin{array}{l}\text { Cylindrical column }(83 \mathrm{~mm} \\
\text { in diameter, } 153 \mathrm{~mm} \mathrm{in} \\
\text { height })\end{array}$ \\
\hline
\end{tabular}

\section{Results and discussion}

\subsection{Scaling behaviour of pure water evaporation}

Figure 1 (a) illustrates the measured cumulative water evaporation from the Hele-Shaw cells packed with sand grains saturated with pure water. The experiments were conducted under 6 different ambient conditions (i.e. at $25{ }^{\circ} \mathrm{C}$ and relative humidity of 30,50 and $70 \%$ and at 35 ${ }^{\circ} \mathrm{C}$ and relative humidity of 30,50 and $70 \%$ ). 

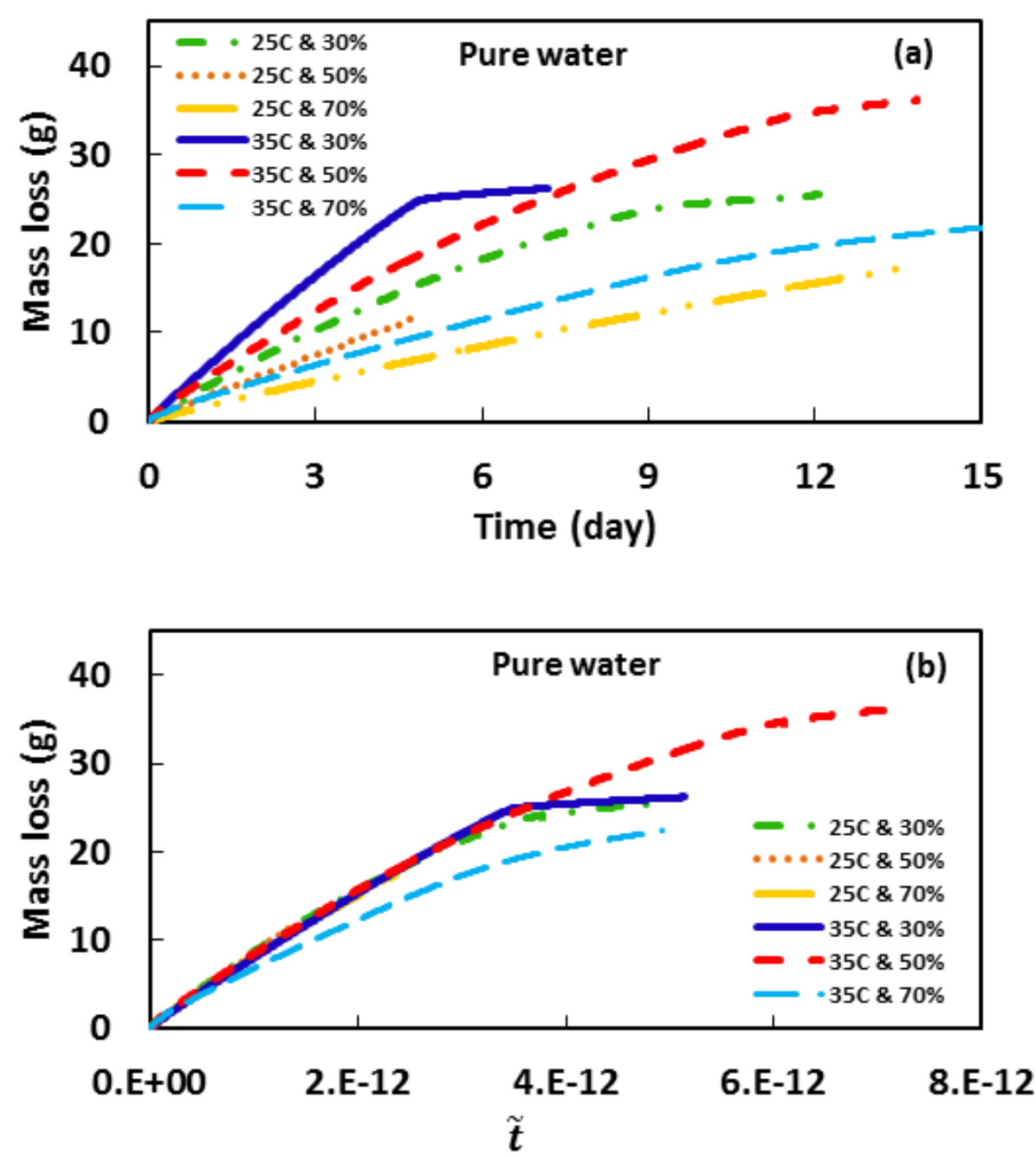

Figure 1. Cumulative evaporative water loss measured during the evaporation process from a Hele-Shaw cell packed with sand grains saturated with pure water versus (a) time and (b) scaled time introduced in Eq. (4). The legend indicates ambient temperature and relative humidity in each round of experiments.

The evaporation rate (i.e. the slope of the mass loss curve) in all cases remains relatively constant in the early stages of the evaporation processes depicted in Figure 1(a). This is typical trend observed during stage- 1 evaporation where the evaporative demand is supplied by liquid transfer from the interior of the porous medium to the surface via capillary induced liquid flow and liquid vaporization at the surface. Similar behaviour has been reported in many other studies (e.g. see Lehmann et al. [2008]; Shokri-Kuehni et al. [2016]). Stage-1 
evaporation will eventually end when the liquid connection with the surface is disrupted due to the competition between capillary, gravity and viscous forces [Lehmann et al., 2008]. This marks the onset of the stage- 2 evaporation when the evaporative flux is limited by vapour diffusion through the porous media [Shokri and Or, 2011] resulting in much smaller evaporative fluxes. This explains the change of the slope in some of the curves presented in Figure 1(a). Figure 1(b) shows the measured mass losses versus $\tilde{t}$, Eq. (4). This figure shows that the measured cumulative mass losses from the sand columns saturated with pure water under different relative humidity and ambient temperature coincide very well if plotted versus $\tilde{t}$. It must be noted that such a scaling behaviour is valid only during/stage- 1 evaporation (when the process is mainly controlled by the liquid vaporization at the surface). Figure 1(b) confirms that the changes in the evaporative mass lossés depicted in Figure 1(a) are the result of the change in relative humidity and ambient temperature and the process is controlled by the external conditions.

\subsection{Scaling behaviour of saline water evaporation}

Figure 2 shows the measured cumulative mass losses from the Hele-Shaw cells packed with sand grains saturated with $1 \mathrm{M} \mathrm{NaCl}$ solution under different ambient temperature and relative humidity The highest and lowest measured evaporation correspond to the highest (35 ${ }^{\circ} \mathrm{C}$ and $\left.30 \%\right)$ and lowest $\left(25{ }^{\circ} \mathrm{C}\right.$ and $\left.70 \%\right)$ evaporative demands, respectively. During saline water evaporation, the $\mathrm{NaCl}$ concentration increases continuously close to the surface. Therefore, the saturated vapour pressure above the surface decreases continuously, Eq. 6 . Thus, contrary to the case of pure water, the evaporation rate from the beginning of the experiments with saline water decreases over time (because the driving force $P_{S}-P_{\infty}$ decreases as a result of the increasing salt concentration). 

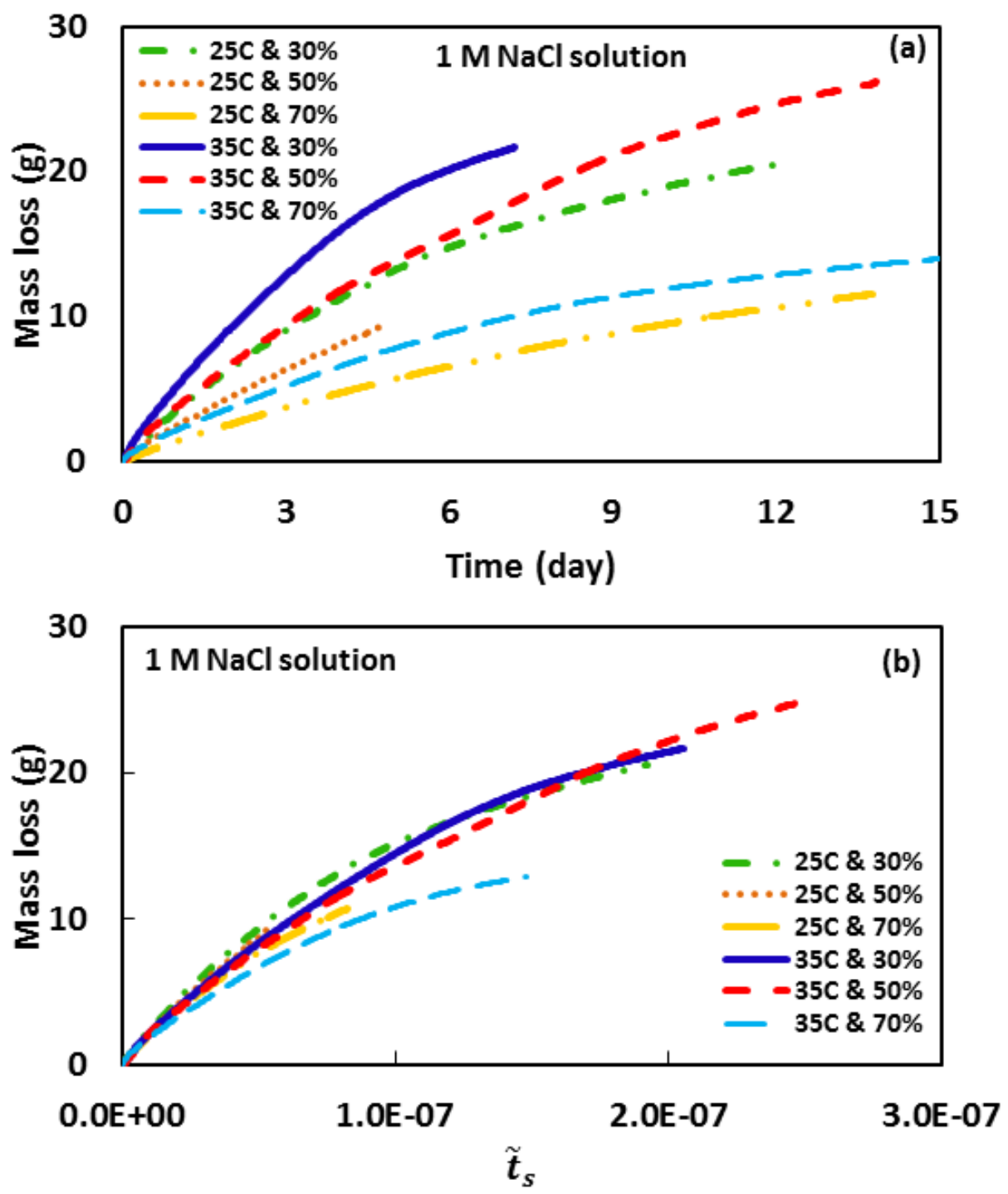

Figure 2. Cumulative evaporative water loss measured during saline water evaporation from a Hele-Shaw cell packed with sand grains saturated with $1 \mathrm{M} \mathrm{NaCl}$ solution versus (a) time and (b) scaled time introduced in Eq. (7). The legend indicates ambient temperature and relative humidity in each round of experiments.

Figure 2(b) illustrates the recorded mass losses under different external conditions (indicated in the legend) versus the rescaled time $\tilde{t}_{s}$. It is remarkable to have all the curves in Figure 2(b) coincided quite well when plotted as a function of the scaling parameter $\tilde{t}_{s}$. This is not an intuitive result because one would expect the formation and growth of precipitated salt at the surface to influence and limit the evaporation flux but this is not what we observed in our 
data (note that the slight differences among the curves illustrated in Figure 2(b) could be related to the changes in the saturated vapour pressure above the surface over time due to the increasing salt concentration at the surface). Figure 3 shows the comparison between the measured evaporation rates during the first 2 days of the experiments (i.e. the slopes of the mass loss curves presented in Figures 1 and 2 averaged over the first two days) under different external conditions for pure and saline water.

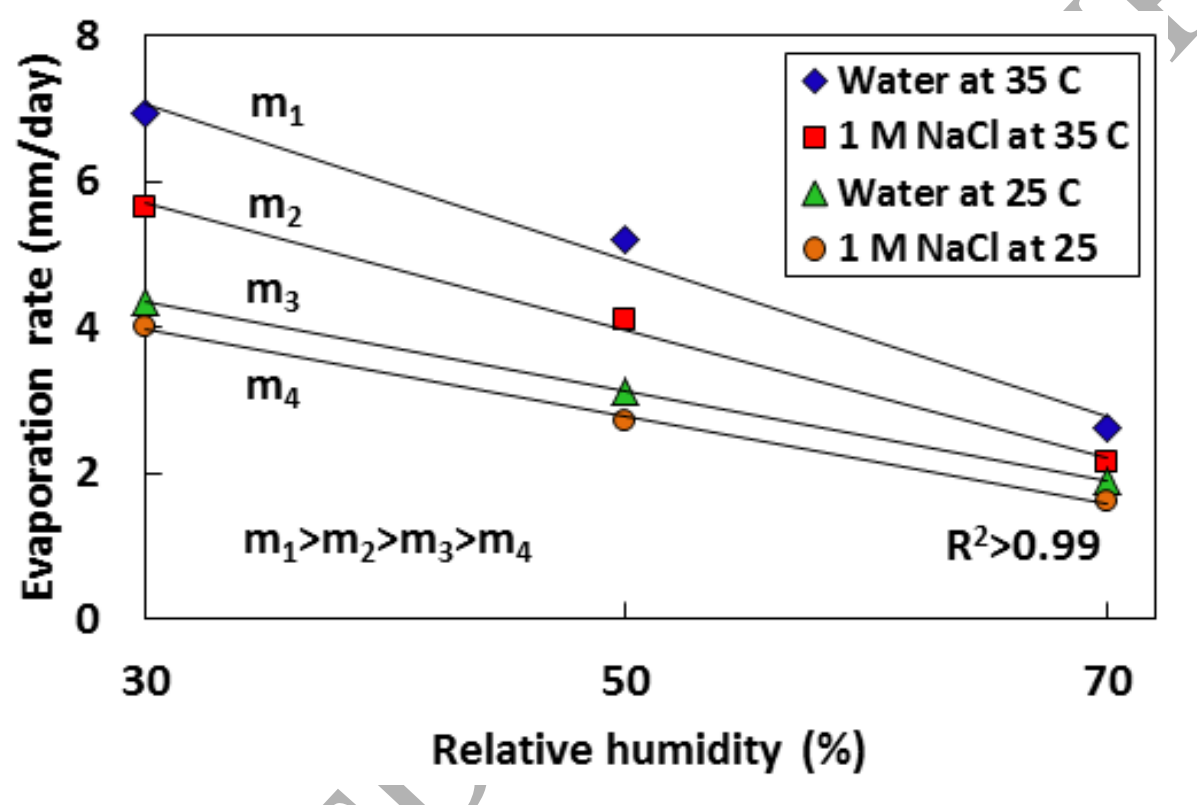

Figure 3. Evaporation rate during the first two days from the onset of the experiments. The value of the evaporation rate was calculated using the slope of the linear lines fitted to the cumulative mass loss curves presented in Figures 1 and 2. The legend indicates the ambient temperature in each round of the experiment and the liquid (water or $1 \mathrm{M} \mathrm{NaCl}$ solution) used to saturate the sand columns. The solid lines indicate the linear fit to the data (in all cases $\left.\mathrm{R}^{2}>0.99\right)$. The slopes of the lines are represented by $\mathrm{m}_{1}, \mathrm{~m}_{2}, \mathrm{~m}_{3}$ and $\mathrm{m}_{4}$.

Figure 3 shows that increasing relative humidity results in decreasing evaporation flux. Under the same ambient temperature, adding salt reduced the evaporative water losses due to the reduced saturated vapour pressure above the surface. The difference between drying rates of 
pure and saline water increased as temperature increased from $25{ }^{\circ} \mathrm{C}$ to $35{ }^{\circ} \mathrm{C}$. This is due to the nonlinear dependency of the saturated vapour pressure and the diffusion coefficient into air on ambient temperature. In any case, the results presented in Figures 2 and 3 illustrate a relatively linear relationship between the evaporation rate from saline solution and the external condition and that the evaporative flux is mainly limited by the external conditions; similar to what is observed in the case of pure water (Figure 1). To have a closer look at the evaporation process from saline porous media, another set of experiments (set\#3; Table 2) were conducted in which cylindrical columns were used and the dynamics of evaporative mass losses together with the salt precipitation at the surface were investigated.

\subsection{Precipitation dynamics and the evaporative mass losses}

A cylindrical column was packed with sand grains saturated with $3 \mathrm{M} \mathrm{NaCl}$ solution. The evaporation experiments were conducted at four different external conditions (indicated as set\#3 in Table 2). The recorded images of the surface of the porous media were used to quantify the part of the surface covered by salt over time. Salt is represented by the white colour in the images. Therefore one could assume the higher the pixel gray value $(\mathrm{GV})$ of the images, the more area is covered by salt. We used the surface gray value of the last image as the reference value to scale the other images as:

Scaled $G V=\frac{\text { Summation of } G V \text { of all pixels in each image }}{\text { Summation of } G V \text { of all pixels in the last image }}$

"Scaled GV" will be always equal to, or less than one (because the last image has the highest GV since the entire surface is covered by salt). Based on the definition of "Scaled GV", a bigger portion of the surface is covered by salt when "Scaled GV" is closer to 1. Applying the same scaling to all images enabled us to quantify the dynamics of surface coverage by salt 
over the course of the experiment. Figure 4 illustrates the evaporative mass losses together with the precipitation dynamics at the surface.

The results show a strong relationship between dynamics of the evaporative mass losses and the surface coverage by salt. A similar correlation was observed by Norouzi Rad and Shokri [2012]. Existence of such a strong correlation may have applications beyond the focus of this paper because it may offer an opportunity to estimate the evaporative mass losses by looking into the salt precipitation dynamics at the surface. The counter-intuitive result presented in Figure 4 is to have a significant portion of the surface covered by salt; yet the cumulative evaporative mass losses are not influenced by the presence of this precipitated salt at the surface. This result suggests that the presence of salt crystals at the surface does not necessarily stop the evaporation process (at least during the early stage of the process). The same conclusion was reached in some recent studies on building materials and glass beads packing (e.g. Eloukabi et al., 2013; Gupta et al., 2014). The reason for this is the porous nature of the precipitated salt (Norouzi Rad et al., 2013). Liquid flows through the precipitated salt via capillary flow keeping the crystals at the surface wet, which contributes to the evaporation. This explains why the evaporative flux is not limited significantly by the presence of the precipitated salt at the surface (as long as it remains wet) and that the curves could be scaled in Figure 2(b). 

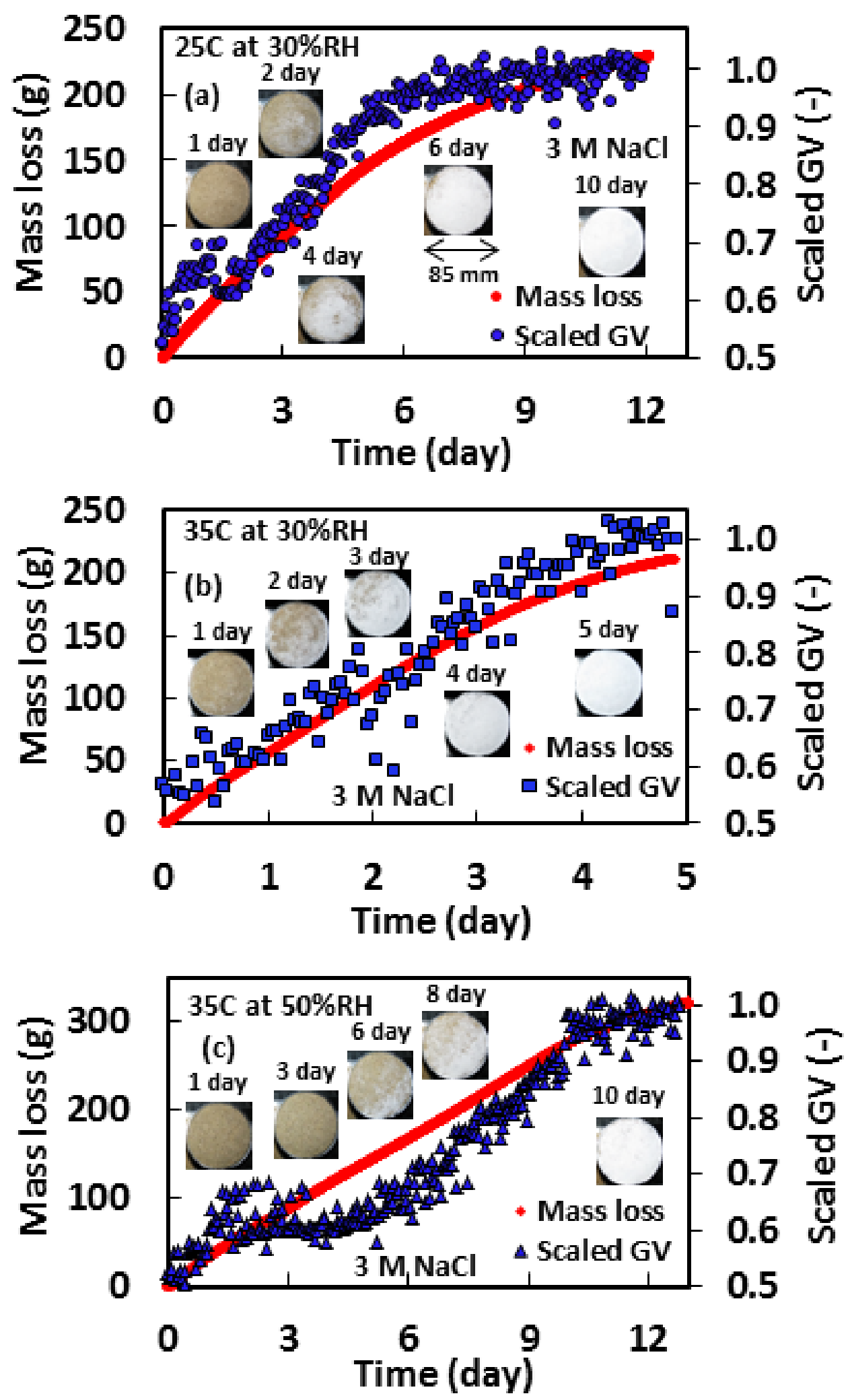

Figure 4. Cumulative evaporative mass losses versus time measured during evaporation from a cylindrical sand column saturated with $3 \mathrm{M} \mathrm{NaCl}$ solution at a) $25^{\circ} \mathrm{C}$ and relative humidity 
(RH) of $30 \%$, b) $35^{\circ} \mathrm{C}$ and relative humidity of $30 \%$ and c) $35^{\circ} \mathrm{C}$ and relative humidity of $50 \%$. Also presented is the scaled gray value $(\mathrm{GV})$ at the surface of the porous media, indicating the surface coverage by precipitated salt. Values closer to 1 indicate a greater fraction of the surface is covered by salt. The insets illustrate typical salt precipitation patterns at different times from the onset of the experiments. The white colour represents precipitated salt at the surface.

To further investigate this, the measured mass losses during evaporation from the columns saturated with $3 \mathrm{M} \mathrm{NaCl}$ solution at an ambient temperature of $25^{\circ} \mathrm{C}$ and relative humidity of 30 and $50 \%$ are presented in Figure 5.
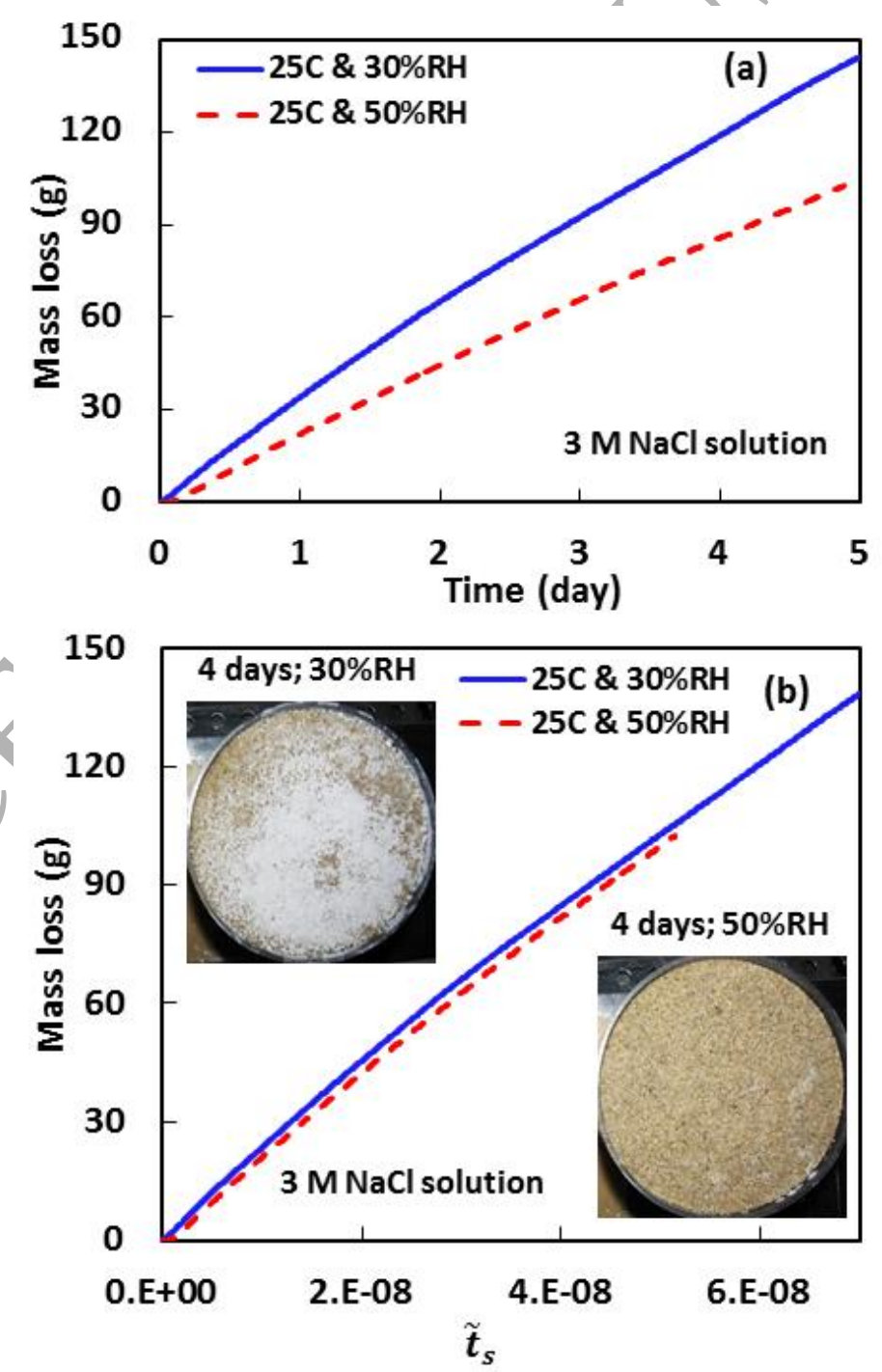
Figure 5. (a) The cumulative mass loss measured during evaporation from cylindrical columns packed with sand saturated with $3 \mathrm{M} \mathrm{NaCl}$ solutions. The experiments were conducted at the constant temperature of $25^{\circ} \mathrm{C}$ and relative humidity of 30 and $50 \%$. (b) The cumulative mass losses presented in section (a) plotted versus the scaled time $\tilde{t}_{s}$ introduced in Eq. 7. The insets illustrate the precipitation patterns at the surface after 4 days from the onset of the experiment. White corresponds to precipitated salt.

The cumulative mass loss from the column placed under $50 \%$ relative humidity is less than that under $30 \%$; this is expected as the driving force for the evaporation is less (Eq. 1). Therefore much more salt was precipitated at the surface of the column placed under $30 \%$ relative humidity. The inset of Figure 5 shows the surface of these two sand columns after 4 days from the onset of the experiment confirming the above statement. Although these two columns have completely different precipitation patterns at the surface, the cumulative mass losses are very close if plotted against the scaled time $\tilde{t}_{s}$ introduced in Eq. 7 . This confirms that the different cumulative mass losses observed in Figure 7(a) are due to the different external conditions and not to the presence or absence of precipitated salt at the surface and that the precipitated salt does not necessarily limit the liquid transfer toward the surface because of its porous nature (at least in the early stages of the process).

\subsection{Effects of type of salt on the evaporation behaviour}

The data obtained from the experiments with $\mathrm{NaCl}, \mathrm{KI}$, and $\mathrm{CaCl}_{2}$ are presented in this section. See Table 2 for detail of the boundary conditions in each round of experiments. Figure 6 illustrates the measured cumulative mass losses. Results show that as salt concentration increased the evaporative mass losses decreased in all cases. When plotting against the scaled time $\tilde{t}_{s}$, the cumulative mass losses recorded during early stages of the process coincide very well in the case of $\mathrm{NaCl}$ and $\mathrm{KI}$. This means the observed differences 
in the recorded mass loss curves are governed by the effects of salt concentration on lowering the vapour pressures (Eq. 6) as other parameters were kept the same in the experiments.
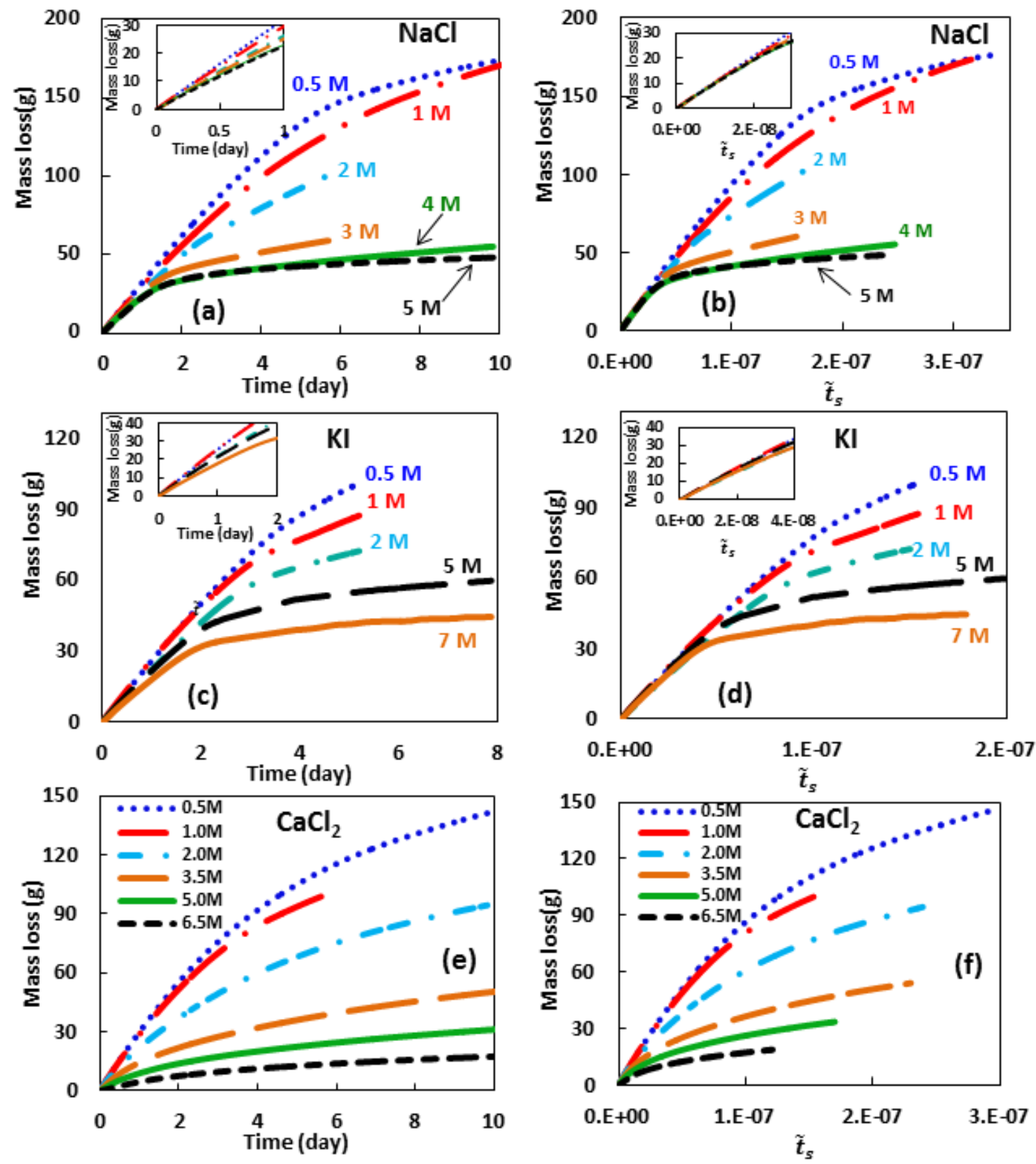

Figure 6. The cumulative mass loss measured during evaporation from the cylindrical columns packed with sand saturated with (a) $\mathrm{NaCl}$, (b) $\mathrm{KI}$ and (c) $\mathrm{CaCl}_{2}$ solutions. (b), (d) and (f) shows the same data (i.e. cumulative mass losses) versus the scaled time $\tilde{t}_{s}$ introduced in Eq. 7. All experiments were conducted at the constant temperature of $35^{\circ} \mathrm{C}$ and relative 
humidity of $25 \%$. Legends indicate the initial salt concentration used to saturate the sand columns. The insets in (a-d) show the same cumulative mass loss data as the main curve but zoomed in to illustrate the trend in the early stages of the process.

Note that in the previous sections variation of the external conditions caused the changes in the evaporative mass losses but in this case it is the change in properties of the solution modifying the evaporation process but all of these effects are already incorporated in the scaled times introduced in Eqs. 4 and 7. In the case of $\mathrm{NaCl}$ and $\mathrm{KI}$, although the curves coincide very well using the scaled times during the early stages of the process (the insets in Figure 6(b) and 6(d)), they cannot be represented by a single curve during the later stages of evaporation. This is likely due to drying of the precipitated salt at the surface which results in the change of the vaporization plane from the surface of the precipitated salt to deeper depths (located either at the interface between the porous media and the precipitated salt or depths below the surface of the porous media). Therefore, the process is no longer controlled by vapour diffusion from the wet salt surface to the air but by a combination of capillary flow from the interface between the wet and partially wet zones in the porous medium up to this new vaporization plane, liquid vaporization at that level and then vapour diffusion through the porous medium and the dried precipitated salt to the air.

$\mathrm{CaCl}_{2}$ shows a different drying behaviour to those observed in the case of $\mathrm{NaCl}$ and $\mathrm{KI}$. Figure 6(e) and (f) show that the recorded cumulative mass losses in the case of $\mathrm{CaCl}_{2}$ do not coincide either in the early or later stages of the evaporation using the scaled time. On top of that, variation of the evaporative mass losses versus salt concentration is much more significant in the case of $\mathrm{CaCl}_{2}$ compared to the other two salts considered in this study. One of the reasons for such behaviour could be attributed to the significant dependency of the 
saturated vapour pressure on salt concentration in the case of $\mathrm{CaCl}_{2}$ compared to $\mathrm{NaCl}$ and KI.

As evaporation proceeds, the salt concentration increases close to the surface; thus the saturated vapour pressure decreases over time. This influences the driving force for evaporation especially in the early stages of the process (when the process is still limited by the external conditions). If $P_{s}$ changes significantly versus concentration, the driving force for liquid vaporization in the early stages of the process changes notably thus resulting in continuous lowering of the evaporation rates. However, if $P_{s}$ does not change significantly versus concentration, then one could describe the evaporation process in the early stages using the scaled times (Eq. 4 and 7). Figure 7(a) shows the variation of $P_{s}$ versus concentration of $\mathrm{NaCl}, \mathrm{KI}$ and $\mathrm{CaCl}_{2}$ at $35^{\circ} \mathrm{C}$ using Eq. (6). 

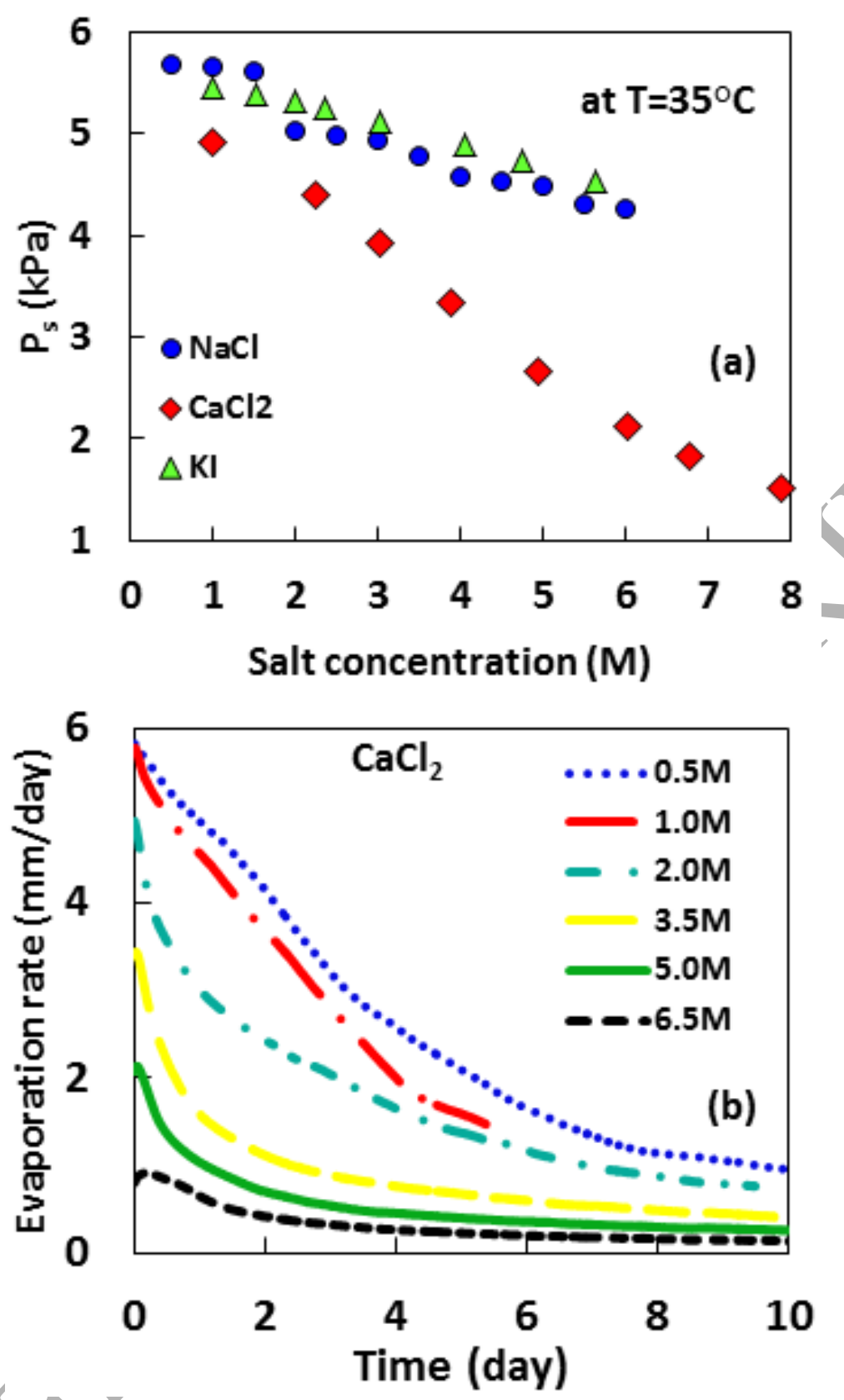

Figure 7. (a) Variation of the saturated vapour pressure $P_{s}$ versus salt concentration at $35^{\circ} \mathrm{C}$. The legend indicates the type of salt. The data were obtained using Eq. (6) and the data presented in Table 1. (b) The evaporation rate versus time measured during evaporation from the sand column saturated with $\mathrm{CaCl}_{2}$ solution. The legend indicates the initial salt concentration in each case.

According to Figure 7(a), $P_{s}$ changes significantly as concentration changes in the case of $\mathrm{CaCl}_{2}$ as opposed to $\mathrm{NaCl}$ and $\mathrm{KI}$. This has significant impact on its evaporation behaviour 
and causes continuous decrease of the evaporation rate from the beginning of the experiment as illustrated in Figure 7(b).

\section{Summary and conclusions}

A comprehensive series of evaporation experiments (using 33 sand columns) were conducted under well-controlled ambient temperatures and relative humidities to understand the effects of external condition as well as type of salt on saline water evaporation from porous media. Our results confirm that during stage- 1 evaporation of pure water, the process is mainly controlled by the ambient conditions. The recorded mass losses in the case of pure water under 6 different external conditions could be represented by a single curve using scaled time $\tilde{t}$.

In addition, our results illustrate the minor impact of the presence of precipitated $\mathrm{NaCl}$ at the surface on saline water evaporation during the early stages of the process. This is because of the porous nature of the precipitated salt at the surface keeping the salt wet (via capillary flow) that contributes to the evaporation process. The recorded mass losses from the columns packed with saline solution with different $\mathrm{NaCl}$ concentrations that experienced different ambient temperature and relative humidity could be represented by a single curve using the scaled time $\tilde{t}_{s}$. The scaling behaviour is valid as long as the surface or the precipitated salt remains wet. This analysis confirms that it is a necessity to understand how the porous structure of precipitated salt evolves during evaporation from porous media and how it influences the subsequent flow and transport processes. Modelling tools introduced in some recent studies [Malmir et al., 2016a; 2016b] will be useful to describe such a phenomenon.

Additionally, using $\mathrm{NaCl}, \mathrm{KI}$ and $\mathrm{CaCl}_{2}$ enabled us to investigate the impact of the properties of the evaporating solution on the evaporation dynamics. Our results highlight the important effect of the relationship between the saturated vapour pressure and salt concentration on the 
general dynamics of the evaporation process. Significant variation of the saturated vapour pressure with respect to the salt concentration in the case of $\mathrm{CaCl}_{2}$ led to decreasing evaporation rate from the very beginning of the experiments because any small increase in salt concentration at the surface (as a result of evaporation) has a notable impact on the saturated vapour pressure in the case of $\mathrm{CaCl}_{2}$ that influences the driving force for vaporization.

\section{Acknowledgement}

We gratefully acknowledge funding by the Leverhulme Trust to support this research (RPG2014-331). We would like to thank Kaicheng Ding, a MEng student in Nima Shokri's research group, for her help with conducting some of the experiments. The data presented in this manuscript will be available freely via sending a request to the corresponding author. The first and last author would also like to acknowledge the contribution and cooperation of Delphi Everest Dana Shokri-Kuehni during this research.

\section{Appendix}

Eq. 6 was fitted to the values derived from Patil et al. (1991) and Clarke and Glew (1985) to obtain the empirical parameters presented in Table 1 . Specifically speaking, in the case of KI and $\mathrm{CaCl}_{2}$, Eqs. 1 to 4 of Patil et al. (1991) were used to obtain saturated vapour pressure as a function of salt concentration at $35^{\circ} \mathrm{C}$. Then Eq. 6 was fitted to the values derived from Patil et al. (1991). As for $\mathrm{NaCl}$, the values of saturated vapour pressure at various temperatures (but not at $35^{\circ} \mathrm{C}$ ) as a function of $\mathrm{NaCl}$ concentration were given as tabulated values in Clarke and Glew (1985). We have used those values to estimate saturated vapour pressure at $35^{\circ} \mathrm{C}$ at the given concentrations in Figure A1 (indicated by symbols). Then Eq. 6 was fitted to these values to obtain the empirical parameters presented in Table 1. 


\section{References}

Aminzadeh, M., and D. Or (2013), Temperature dynamics during nonisothermal evaporation from drying porous surfaces, Water Resour. Res., 49, 7339-7349.

Austin, J., L. Zhang, R.N. Jones, P. Durack, W. Dawes, P. Hairsine (2010), Climate change impact on water and salt balances: an assessment of the impact of climate change on catchment salt and water balances in the Murray-Darling Basin, Australia, Climatic Change, $100,607-631$.

Ben Neriah, A., S. Assouline, U. Shavit, N. Weisbrod (2014), Impact of ambient conditions on evaporation from porous media, Water Resour. Res., 50, 6696-6712.

Bergstad, M., N. Shokri (2016), Evaporation of NaCl solution from porous media with mixed wettability, Geophys. Res. Lett., 43, 4426-4432.

Buck, A. L. (1981), New equations for computing vapor pressure and enhancement factor, J. Appl. Meteorol., 20(12), 1527-1532,

Clarke, E.C.W., D.N. Glew (1985), Evaluation of the Thermodynamic Functions for Aqueous Sodium Chloride from Equilibrium and Calorimetric Measurements below $154{ }^{\circ} \mathrm{C}$, j. Phys. Chem. Ref. Data, 14(2), 489-610.

Deinlein, U., A.B. Stephan, T. Horie, W. Luo, G. Xu, J.I. Schroeder (2014), Plant salttolerance mechanisms, Trends in Plant Science, 19(6), 371-379.

Eloukabi, E., N. Sghaier, S. Ben Nassrallah, and M. Prat (2013), Experimental study of the effect of sodium chloride on drying of porous media: The crusty-patchy efflorescence transition, Int. J. Heat Mass Transfer, 56, 80-93. 
Geng, X., M.C. Boufadel, N.L Jackson (2016), Evidence of salt accumulation in beach intertidal zone due to evaporation, Sci. Rep., 6, 31486; doi: 10.1038/srep31486.

González-Alcaraz, M.N., F.J. Jiménez-Cárceles, Y. Álvarez, J. Álvarez-Rogel (2014), Gradients of soil salinity and moisture, and plant distribution, in a Mediterranean semiarid saline watershed: a model of soil-plant relationships for contributing to the management, Catena, 115, 150-158.

Gupta, S., H.P. Huinink, L. Pel, K. Kopinga (2014), How Ferrocyanide Influences $\mathrm{NaCl}$ Crystallization under Different Humidity Conditions, Cryst. Growth Des., 14 (4), 1591-1599.

Haghighi, E., E. Shahraeeni, P. Lehmann, and D. Or (2013), Evaporation rates across a convective air boundary layer aredominated by diffusion, Water Resour. Res., 49, 16021610.

Jambhekar, V.A., R. Helmig, Natalie Schroder, N. Shokri (2015), Free-flow-porous-media coupling for evaporation-driven transport and precipitation of salt, Trans. Porous. Med., 110(2), 251-280.

Jambhekar, V.A., E. Mejri, N. Schröder, R. Helmig, N. Shokri (2016), Kinetic approach to model reactive transport and mixed salt precipitation in a coupled free-flow-porous-media system, Trans. Porous. Med., 114(2), 341-369.

Lehmann, P., S. Assouline, and D. Or (2008), Characteristic lengths affectingevaporative drying of porous media, Phys. Rev. E, 77, 056309,doi:10.1103/PhysRevE.77.056309.

Malmir, H., M. Sahimi, M.R. Rahimi Tabar (2016a), Microstructural characterization of random packings of cubic particles, Sci. Rep., 6, 35024, DOI: 10.1038/srep35024. 
Malmir, H., M. Sahimi, M.R. Rahimi Tabar (2016b), Packing of nonoverlapping cubic particles: Computational algorithms and microstructural characteristics, Phys. Rev. E, 94, 062901.

Norouzi Rad, M., N. Shokri (2012), Nonlinear effects of salt concentrations on evaporation from porous media, Geophys. Res. Lett., 39, L04403.

Norouzi Rad, M., N. Shokri, M. Sahimi (2013), Pore-Scale Dynamics of Salt Precipitation in Drying Porous Media, Phys. Rev. E, 88, 032404.

Odeh, I.O.A., A. Onus (2008), Spatial Analysis of Soil Salinity and Soil Structural Stability in a Semiarid Region of New South Wales, Australia, Environmental Management, 42, 265-278.

Or, D., P. Lehmann, E. Shahraeeni, N. Shokri (2013), Advances in soil evaporation physics a review, Vadose Zone J., 12(4), doi:10.2136/vzj2012.0163.

Patil, K.R., A.D. Tripathi, G. Pathak, S.S. Katti (1991), Thermodynamic properties of aqueous electrolyte solutions. 2. Vapor pressure of aqueous solutions of sodium bromide, sodium iodide, potassium chloride, potassium bromide, potassium iodide, rubidium chloride, cesium chloride, cesium bromide, cesium iodide, magnesium chloride, calcium chloride, calcium bromide, calcium iodide, strontium chloride, strontium bromide, strontium iodide, barium chloride, and barium bromide, J. Chem. Eng. Data, 1991, 36 (2), 225-230

Salvucci, G.,D., and P. Gentine (2013), Emergent relation between surface vapor conductance and relative humidity profiles yields evaporation from weather data, Proc. Natl. Acad. Sci. U.S.A., 110 (16), 6287-6291. 
Schlünder, E.-U. (1988), On the mechanism of the constant drying rate period and its relevance to diffusion controlled catalytic gas phase reactions, Chem. Eng. Sci., 43, 26852688.

Sghaier, N., and M. Prat (2009), Effect of efflorescence formation on drying kinetics of porous media, Transp. Porous Med., 80, 441-454.

Shokri-Kuehni, S.M., E. Bou-Zeid, C. Webb, N. Shokri (2016), Roof cooling by direct evaporation from a porous roof layer, Energy and Buildings, 127, 521-528.

Shokri, N., P. Lehmann, P. Vontobel, D. Or (2008), Drying front and water content dynamics during evaporation from sand delineated by neutron radiography, Water Resour. Res., 44, W06418.

Shokri, N., and D. Or (2011), What determines drying rates at the onset of diffusion controlled stage-2 evaporation from porous media?,Water Resour. Res., 47, W09513, doi:10.1029/2010WR010284.

Shokri, N., P. Lehmann, D. Or (2009), Critical evaluation of enhancement factors for vapor transport through unsaturated porous media, Water Resour. Res., 45, W10433.

Smits, K. M., V. V. Ngo, A. Cihan, T. Sakaki, and T. H. Illangasekare (2012), An evaluation of models of bare soil evaporation formulated with different land surface boundary conditions and assumptions, Water Resour. Res., 48, W12526, doi:10.1029/2012WR012113.

Soulié, V. S. Karpitschk, F. Lequien, P. Prené, T. Zemb, H. Moehwald, H. Riegler (2015), The evaporation behavior of sessile droplets from aqueous saline solutions, Phys. Chem. Chem. Phys.,17, 22296-22303. 
Vanderborght, J., T. Fetzer, K. Mosthaf, K. M. Smits, and R. Helmig (2017), Heat and water transport in soils and across the soil-atmosphere interface: 1. Theory and different model concepts, Water Resour. Res., 53, doi:10.1002/2016WR019982. 